\title{
Wie die MMW zu ihrem Namen kam
}

Chefredakteur Dr. med. Dirk Einecke

\section{BAKTERIOLOGIE}

\section{Reiche Flora auf Frauenhänden}

Forscher der Universität Colorado haben bei 51 Studenten die Flora der Handflächen untersucht. Im Durchschnitt konnten auf jeder Hand 150 Bakterienarten nachgewiesen werden. Bei allen Probanden zusammen fanden sich mehr als 4700 verschiedene Spezies. Nur etwa $17 \%$ der Bakterien, die bei einem Individuum auf einer Handfläche nachgewiesen werden konnten, waren auch auf der Gegenseite vorhanden. Bei Frauen war die Artenvielfalt wesentlich ausgeprägter als bei männlichen Probanden. Händewaschen änderte die Zusammensetzung der Handflächenflora allenfalls kurzfristig. Dies sollte aber nicht als Aufforderung verstanden werden, diese simple Hygienemaßnahme in Zukunft zu unterlassen, so die Forscher.

Proceedings of the National Academy of Sciences (DOI: 10.1073/pnas.0807920105)

\section{MYOKARDINFARKT ÜBERLEBT}

\section{Droht jetzt der plötzliche Herztod?}

Die Gefahr, nach einem überstandenen Herzinfarkt am plötzlichen Herztod zu versterben, ist in den letzten 30 Jahren deutlich zurückgegangen. Ein erhöhtes Risiko findet sich vor allem in den ersten 30 Tagen nach dem Infarkt und bei den Patienten, die eine Herzinsuffizienz entwickeln. Das ist das Ergebnis einer Registerstudie mit 2997 Patienten, die zwischen 1979 und 2005 einen Herzinfarkt überlebt hatten. In den ersten 30 Tagen war die Inzidenz des plötzlichen Herztodes mit 1,2\% viermal höher als in der Allgemeinbevölkerung. Nach diesem Zeitpunkt lag die Rate sogar etwas unter dem Durchschnitt. Ein Warnsignal für einen drohenden plötzlichen Herztod ist die Ausbildung einer Herzinsuffizenz, nicht aber das wiederholte Auftreten von Ischämien.

JAMA 2008;300:2022-29

\section{GERINGERES RISIKO}

\section{Schützt Migräne vor Brustkrebs?}

Migränepatientinnen haben einer neuen Studie zufolge ein um 30\% niedrigeres Brustkrebsrisiko als Frauen ohne solche Kopfschmerzen. Insbesondere Hormonrezeptor-positive Tumoren treten bei ihnen seltener auf. Für einen hormonellen Hintergrund dieser Korrelation spricht die Tatsache, dass auch bei der Migräne hormonelle Auslöser bekannt sind und dass $80 \%$ der Patientinnen im dritten Schwangerschaftstrimester, in dem die Östrogenspiegel am höchsten sind, keine Migräneanfälle haben. In der Studie waren die Daten von 3412 Frauen untersucht worden, von denen 1938 an Brustkrebs erkrankt waren. Dabei zeigte sich das signifikant niedrigere Brustkrebsrisiko bei Frauen, die über Migräneattacken berichteten.

Cancer Epidemiology, Biomarkers and Prevention Nov. 2008

\section{JAHRE MMW \\ Von den „intelligenten“ Wurzeln Ihrer Fortbildungslektüre}

Von 1854 bis 1877 erschien die MMW unter dem ebenso bemerkenswerten wie auch heute noch zutreffenden Titel „Aerztliches Intelligenz-Blatt“ - eine Wochenzeitschrift also für den wissenschaftlich gebildeten Arzt. Auch 150 Jahre nach der Gründung schätzt der typische Leser in der MMW die hohe Kompetenz in der wissenschaftlichen Fortbildung: In den jährlichen Umfragen unter 1000 Hausärzten, Allgemeinärzten und Internisten attestierten zuletzt $82 \%$ der Befragten der MMW eine hohe „Wissenschaftlichkeit“ - der Spitzenwert in der Befragung. Alle anderen Zeitschriften und Zeitungen für diese Ärztegruppe erreichten hier nur einen Durchschnittswert von 40\%.

1880 erhielt das „Ärztliche IntelligenzBlatt“ zunächst den Untertitel „Münchener Medicinische Wochenschrift". 1886 wurde „MMW“ Haupttitel. 1904 verschwand das „Ärztliche IntelligenzBlatt" auch im Untertitel. Die Namens-

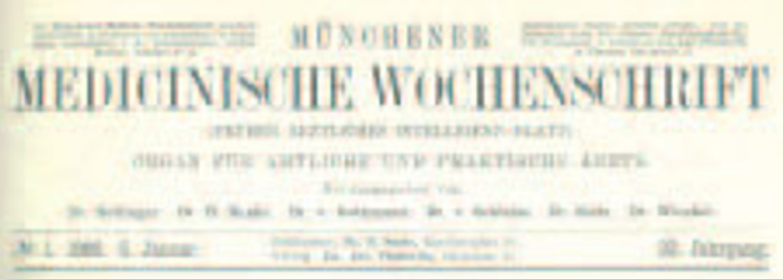

Hier einige Beispiele wichtiger Publikationen nach der Jahrhundertwende:

1911 Paul Ehrlich: Die Salvarsantherapie

1912 Emil von Behring: Die klinische Bedeutung der Proteinüberempfindlichkeit

änderung erschien den damaligen Herausgebern notwendig, um die Entwicklung des zunächst eher regional ausgerichteten amtlichen Mitteilungsblattes in eine nationale und dann auch internationale Fortbildungs- und Publikationszeitschrift mit einem anspruchsvollen, wissenschaftlichen Profil zu betonen.

Diese Rechnung ging auf: Die Auflage verdoppelte sich innerhalb von kurzer Zeit von 750 auf 1500 . Bis 1900 verzehnfachte sie sich auf 15000 . Gleichzeitig stieg die Zahl bedeutender medizinischer Publikationen sprunghaft an. Allein zwischen 1888 und 1938 wurden in der MMW 35000 medizinische Originalarbeiten publiziert, darunter die Beobachtungen zahlreicher Nobelpreisträger.
1913 Ferdinand Sauerbruch: Die Beeinflussung von Lungenerkrankungen durch künstliche Lähmung des Zwerchfells 1915 Karl Friedrich Wenckebach: Herzarrhythmie 1918 Die „Spanische Grippe“ - Sitzung des Ärztlichen Vereins München 1925 August Bier. Homöopathie 1929 Hermann Knaus: Über den Zeitpunkt der Konzeptionsfähigkeit des Weibes

1931 Werner Forßmann: Kontrastdarstellung des lebenden Herzens

Weitere berühmte Mediziner und ihre MMW-Publikationen werden in der Jubiläumsausgabe der MMW vom 27. November vorgestellt. 